\title{
A relação generificada entre o zoneamento urbano do transporte público e as implicações para a provisão de banheiros públicos*
}

\author{
The Gendered Relationship between Urban Land-Use Transportation \\ Planning and the Implications for Public Toilet Provision
}

\author{
Clara Henrietta Greed \\ University of the West of England \\ claragreed@aol.com
}

\section{Resumo}

Este artigo analisa a relação entre a provisão de banheiros públicos e os sistemas de transportes terrestres urbanos, associado as 'diferentes' necessidades das mulheres, tendo como referência o Reino Unido, bem como as preocupações compartilhadas internacionalmente. 'Banheiros' são os componentes de gênero finais do ambiente construído e uma das fronteiras remanescentes da desigualdade sexual. As mulheres, historicamente, têm menos provisões de banheiros públicos do que os homens. Embora as mulheres sejam a maioria da população (52\%), suas necessidades raramente são levadas em conta na realização da política urbana. Há uma necessidade de relacionar a localização e provisão do banheiro às questões de gênero, porque as mulheres são mais propensas a estarem fora de casa com as suas famílias, bebês, crianças pequenas e idosos. Banheiros públicos são o elo que falta na criação de cidades sustentáveis, acessíveis e equitativas. Se o governo quer que as pessoas abandonem seus automóveis e voltem para o transporte público, caminhem e andem de bicicleta (WDS, 2005) é essencial fornecer banheiros públicos nas estações ferroviárias, pontos de ônibus, terminais de transporte, ciclovias e centros da atividade como mercados, shopping centers e zonas de emprego. Se melhores projetos e ações forem desenvolvidos para as mulheres, então é provável que um grande número de outros grupos de desfavorecidos sejam beneficiados também, os quais compartilham semelhantes problemas de acesso a um banheiro decente, incluindo idosos e pessoas com deficiência.

Palavras-chave: banheiros públicos; gênero; planejamento; transportes.
Abstract

This paper looks at the relationship between public toilet provision and urban land-use transportation systems in respect of the 'different' needs of women, with reference to the UK and to internationally-shared concerns. 'Toilets' are the ultimate gendered component of the built environment and one of the remaining frontiers of sexual inequality. Women, historically, have less public toilet provision than men, and although women comprise the majority of the population $(52 \%)$ their needs are seldom taken into account in urban policy making. There is a need to relate toilet location and provision to gender considerations because women are more likely to be the ones out and about with their families, babies, small children and the elderly. Public toilets are the missing link in creating sustainable, accessible and equitable cities. If the government wants to get people out of their cars and back on to public transport, walking, and cycling (WDS,2005) then it is essential to provide public toilets in railway stations, bus stops, transport termini, and in relation to footpaths, cycle tracks and centres of human activity, such as markets, shopping centres and employment zones. If better provision and design is developed for women, then it is likely to benefit a large number of other disadvantaged groups too, who share similar access and provision problems, including the elderly, those with disability and everyone, male or female, who needs a decent toilet.

Keywords: public toilets; gender; planning; transport. 
A sustentabilidade tem sido uma força motriz essencial da política de planejamento por mais de 20 anos (BRUNTLAND, 1987; DCLG, 2005). Entretanto, muitas pessoas que descobriram as supostas políticas sustentáveis (especialmente as políticas preocupadas com a redução emissão de carbono pelos transportes), preocupadas com a redução do uso de carros e o aumento dos deslocamentos de transportes públicos, tornaram suas vidas diárias mais difícil e não necessariamente isso lhes permitiu adotar um estilo de vida mais verde. Na verdade, muitas vezes, parece haver um conflito entre a sustentabilidade ambiental e a criação de cidades acessíveis, inclusivas e justas para todos. Isso ocorre porque as necessidades humanas mais básicas e os fatores sociais são ignorados, tais como a necessidade de banheiros públicos, lugares para sentar e áreas de repouso, ambientes seguros e áreas acessíveis para pedestres. A definição original de sustentabilidade na Declaração do Rio (ONU, 1992; BUCKINGHAN-HATFIELD, 2000), inclui três componentes: viabilidade econômica, equidade social e sustentabilidade ambiental (prosperidade, pessoas, lugar). Entretanto, tem havido uma ênfase exagerada nos aspectos ambientais, à custa dos aspectos sociais e em detrimento de alcançar projeto urbano inclusivo. Além disso, a política de sustentabilidade é frequentemente desenvolvida em um nível muito alto, em relação a questões ambientais estratégicas, sem quaisquer ligações com as necessidades práticas locais e padrões de deslocamento de pessoas comuns (GREED, 2008).

Este trabalho vincula a provisão de banheiros públicos com os 'aspectos sociais de planejamento', procurando responder à clássica pergunta da geografia urbana: "quem recebe o quê, onde, por quê e como?" (HARVEY, 1975; MASSEY, 1984). Tais questões estão relacionadas ao efeito das diferenças de gênero na natureza do ambiente construído (GREED, 1994a; 2005a; 2005b,). Um fator determinante em dar formas às cidades é a natureza da política de planejamento e, portanto, da perspectiva e "visão de mundo" dos urbanistas, projetistas, arquitetos, engenheiros de transporte e os próprios legisladores de políticas urbanas (GREED, 1994a). O fato de que as mulheres ainda sejam minoria nessas profissões (CIC, 2009), ainda hoje há pouco reconhecimento das questões de gênero nas tomadas de decisões, como demonstrado por Jarvis et al (2009).

$\mathrm{Na}$ primeira parte do artigo, eu explico como as mulheres estão em desvantagem pelos atuais padrões de zoneamento urbano e pela sustentabilidade liderada por políticas de transportes. Questiono como os deslocamentos e atividades femininas se encaixam nessas configurações urbanas. $\mathrm{Na}$ segunda parte do artigo, me concentro em um aspecto que pode tornar as cidades mais funcionais e confortáveis para mulheres e homens, sem serem impedidos pelo controle da bexiga: a provisão de banheiros públicos (HANSON, et al, 2007). Estabeleci uma abordagem política estratégica para assegurar banheiros públicos adequados, explicando a necessidade de uma hierarquia espacial de banheiros para atender às necessidades das mulheres e dos homens. Conclui-se, que tal provisão facilitaria o desenvolvimento de uma cidade mais sustentável. Deve-se notar que, embora haja grandes problemas com os banheiros públicos no mundo em desenvolvimento, este trabalho está principalmente preocupado com a situação em países desenvolvidos, ocidentais, em particular o Reino Unido . No passado o Reino Unido era líder mundial em engenharia sanitária e desenvolvimento de infraestrutura, mas atualmente tem experimentado um declínio nos serviços públicos e falta de investimentos, mesmo que nunca tenham atendido adequadamente as necessidades das mulheres (GREED, 2003; ABL, 2006).

O gênero para esse trabalho pode ser definido como os papéis e deveres culturais atribuídos a mulheres e homens na sociedade, independentemente do sexo biológico. Por exemplo, as mulheres ainda são as principais responsáveis pelos cuidados das crianças em nossa sociedade. Entretanto, mesmo se os homens assumissem esses papéis tradicionais femininos, eles também seriam susceptíveis a encontrar as mesmas dificuldades no ambiente construído (PANELLI, 2004).

Os problemas de 'mulheres e a cidade' já foram amplamente documentados, mas a situação pouco mudou (STIMPSON, et al, 1981; MATRIX, 1984; LITTLE, et al, 1988; WHATMORE e LITTLE, 1988; ROBERTS, 1991; GREED, 1994; BOOTH, et al, 1996; EUROFEM, 1998; BUCHINGHAN HATFIELD, 2000; DARKE, et al, 2000; ANTHONY, 2001; HAYDEN, 2002; REEVES, 2005; UTENG e CRESSWELL, 2008; JARVIS, et al, 2009; entre outros). Eu escolhi as questões sanitárias para este artigo, porque, 'banheiro' é o artefato cultural básico que reúne considerações biológicas, sexuais e de gênero, ou seja, diferenças fisiológicas práticas entre os usuários (GERSHENSON e PENNER, 2009; CAVANAGH, 2010) e restrições culturais. Em nossa cultura são mulheres as pessoas mais prováveis de estarem acompanhados por crianças pequenas, bebês e parentes idosos. Apesar disso, as mulheres recebem menos provisão de banheiros pelas políticas de distribuição dominadas pelos homens (GREED, 2003; MOLOTCH e NOREN, 2010). Todos os tipos de pessoas sofrem com a falta de instalações e se 
beneficiariam de uma melhor provisão, incluindo os idosos, pessoas com deficiência, sem-tetos, turistas e visitantes de fora da cidade, visto que gênero, cruza, sobrepõe e relaciona-se com todos estas outras características pessoais (BAGILHOLE, 2009).

\section{A natureza generificadla de forma urbana e planejamento}

\section{A Estrutura das Cidades}

Durante muitos anos o planejamento das cidades foi baseado no zoneamento e separação de usos da terra, criando distâncias desnecessárias entre a casa e o trabalho, gerando insustentáveis padrões de deslocamento entre essas unidades de uso. $\mathrm{O}$ planejamento da reconstrução pós Segunda Guerra Mundial no Reino Unido priorizou a remoção de casas e a dispersão da indústria, criando áreas residenciais e instalações públicas, apoiando a baixa densidade e o desenvolvimento suburbano em torno das cidades. Isso criou extensas distâncias de deslocamentos entre áreas de trabalho e bairros residenciais, notadamente para as mulheres (ROBERTS, 1991). Os governos subsequentes favoreceram a utilização do automóvel e a 'americanização das cidades britânicas' (e certamente muitas outras cidades europeias e do mundo), embora as urbanistas norte-americanas já haviam advertido contra os problemas de descentralização urbana, zoneamento excessivo e cidades onde os carros predominam (STIMPSON, et al, 1981). Bairros inteiros de cidades foram demolidos para dar lugar à autoestradas urbanas e a estacionamentos de carros para o predominante habitual usuário de carros, do sexo masculino a partir da década de 1960.

Assim, uma infraestrutura urbana baseada em automóveis e padrões dispersos de uso da terra foram desenvolvidos, enquanto o transporte público foi relegado. Até o final do século XX uma série de ações, inclusive o desenvolvimento de shoppings centers, hipermercados, parques empresariais e de lazer fora da cidade, ao lado de autoestradas, enquanto as escolas, hospitais e serviços das autarquias locais foram todos descentralizados em nome da eficiência, prejudicando o processo de viabilidade dos já existentes centros das cidades e tradicionais municípios. Todas essas políticas dificultaram o deslocamento para fora de sua área local e também aumentaram o congestionamento do tráfego e os tempos de deslocamento das pessoas entre diferentes zonas da cidade para executar suas tarefas diárias. Assim, possuir um automóvel é uma necessidade virtual, especialmente em cidades onde o transporte público tem sido severamente reduzido, as diferentes zonas da cidade muito dispersas e as instalações essenciais como lojas e amenidades já não estão a curta distância.

As mulheres têm sido particularmente afetadas por essas mudanças em cidades com um padrão de organização predominantemente masculino. Os diferentes papéis e responsabilidades entre os gêneros masculino e feminino geram desiguais padrões de deslocamentos entre eles e, portanto, necessidades singulares (COLEMAN, 2000; ANTHONY, 2001; HAYDEN, 2002). Embora as mulheres constituam a maioria da população $(52 \%$ no Reino Unido, e até $55 \%$ em algumas grandes cidades como Birmingham e Manchester) (ONS, 2010) ainda assim, os urbanistas e legisladores de políticas urbanas concebem a população feminina como uma pequena minoria e continuam a planejar as cidades para as necessidades do trabalhador do sexo masculino.

As mulheres são a maioria dos usuários do transporte público no Ocidente, pois elas são a minoria no uso de automóvel privado e, portanto são as mais afetadas pelos problemas dos sistemas de transporte público mal projetados. Esse é problema que cresce internacionalmente conforme a urbanização moderna se acelera (KWAN, 1999).

As mulheres gastam muito do seu tempo esperando ônibus e trens, como já validados por uma extensa gama de pesquisas qualitativas e quantitativas (DFT, 2000; HAMILTON, et al, 2005; UTENG e CRESSWELL, 2008; JARVIS, et al, 2009; ROBERTS e ELDRIDGE, 2009). As mulheres têm sido mal servidas por políticas de planejamento, que fazem pouco para reconhecer as 'diferentes' necessidades e padrões de deslocamento entre homens e mulheres, no desenvolvimento da política de uso da terra (DARKE, et al, 2000; REEVES, 2005). O cuidado com os filhos é de responsabilidade predominantemente feminina, bem como o trabalho doméstico e a realização de compras para abastecer a casa, embora ainda a maioria das mulheres também trabalhe fora de casa (BOOTH, et al, 1996; REEVES, 2005; FINCHER e IVESON, 2008; UTENG e CRESSWELL, 2008; ESRC, 2011).

\section{As Diferenças nas Jornadas das Mulheres e Atividades Diárias}

Devido às diferenças de 'jornada de trabalho' entre homens e mulheres, elas são mais susceptíveis as maiores complexidades e são multiusuárias em comparação com a tradicional ideia do ininterrupto e mono deslocamento (ir e voltar do trabalho), realizado por trabalhadores de tempo integral do sexo masculino. As necessidades de uma multiusuária são 
muito mais difíceis de serem atendidas em cidades estruturadas em torno de prioridades de zoneamento do passado e descentralização (LENCLOS, 2002; REEVES, 2005; WARBURTON, 2009), focadas no deslocamento único entre área residencial e de trabalho.

A cadeia complexidade de deslocamento e a realização de multitarefas são as principais características de deslocamento da mulher e um resultado inevitável de tentar conciliar seus deveres domésticos e de trabalho fora de casa (ROSENBLOOM, 1989; DOBBS, 2005; HAMILTON, et al, 2005; MCGUCKIN e MURAKAMI, 2007). Essa diferença de gênero tem sido o tema de séria investigação tanto por pesquisadores de transporte masculinos e femininos (KWAN, 1999; UTENG e CRESSWELL, 2008; HENSHER e REYES, 2010).

Por exemplo, a cadeia de deslocamento de uma mulher pode ser a seguinte: uma mulher pode sair de casa, passar pela creche, escola ou babá para então ir ao trabalho. Na volta, sai do local de trabalho, passa na escola, creche ou babá e volta para casa, resultando em uma complexa cadeia de deslocamento. Este itinerário diário é difícil de conseguir quando as áreas de empregos e residências foram separadas pelo tradicional zoneamento de uso da terra, baseadas em percepções masculinas de funcionalidade espacial (HANSON e PRATT, 1995; UTENG e CRESSWELL, 2008). Para as mulheres uma série de fatores entram em jogo em seu deslocamento urbano em menor proporção que para os homens, tais como segurança pessoal, vulnerabilidade a ser vítimas de assalto e estupro, iluminação pública, condições das calçadas para acessibilidade e praticidade, pois muitas vezes estão acompanhadas de idosos ou crianças pequenas (BOOTH, et al, 1996). As jornadas de deslocamento das mulheres são mal atendidas pelos sistemas de transporte público que foram projetados de forma radial e em tempo integral, imaginando o fluxo de trabalhadores durante os horários de pico. Assim, os serviços de transporte são mais limitados para mulheres trabalhadoras de meio expediente ou de horários que não correspondem à jornada de trabalho padrão. Por exemplo, antes da hora do rush começar, faxineiras já trabalharam várias horas em escritórios e as operárias de fábricas já saíram cedo e se deslocaram para fábricas na periferia da cidade (BROWNILL, 2000). É claro que a má qualidade dos serviços de transporte também afetam homens, idosos e pessoas com deficiência (IMRIE e HALL, 2001; AGE CONCERN, 2007; SCHOMOCKER, et al, 2010). Mas as mulheres são desproporcionalmente afetadas porque ainda superam os homens como passageiras de ônibus (MCGUCKIN e MURAKAMI, 2007) e, muitos de seus deslocamentos são feitos em cadeia (HENSHER e REYES, 2010), em horários fora de pico, em locais menos frequentes e em trajetos inter suburbanos, que não são priorizados pelas empresas de ônibus, mais preocupadas com deslocamentos na hora de pico e em direção aos centros das cidades e vice-versa (HAMILTON, et al, 2005; UTENGO e CRESSWELL, 2008).

Há ainda um problema particular no planejamento urbano que é 'o horário de funcionamento da escola'. Levar os filhos para a escola pela manhã é uma atividade predominantemente feminina. Esta atividade contribui apenas com $15 \%$ do tráfego da hora do rush, mas é amplamente condenada, por 'tumultuar as ruas' (HAMILTON, 2000; HAMILTON, et al, 2005; DOBBS, 2005).

Claro que se pode dizer "bem, alguns homens seguem o horário de funcionamento da escola muito bem" e, sem dúvida alguma o seguem. Eles também experimentam os mesmos problemas que as mulheres ao fazer isso, tornando o caso ainda mais importante para mudanças (SKINNER, 2005). Entretanto, as mulheres são a maioria nesse processo de deslocamento para a escola, como mostrado nas pesquisas de Dobbs (2005), Pickup e Whipp (1989), TUC (2002) e Hine e Grieco (2003). Muitas mulheres acham que é impossível usar o transporte público para levar seus filhos para a escola e, em seguida, ir para o trabalho. Alegam que não há tempo para esperar por ônibus pouco frequentes e, além disso, há muitos trajetos que não conectam locais escolares e de trabalho. Assim, elas usam carros, mesmo que mal tenham condições para isso. Mas aquelas que usam o transporte público também podem ser acusadas de "sobrecarregar o sistema" e aglomerar os veículos destinados aos usuários habituais (LENCLOS, 2002).

\section{Novos Problemas e Sustentabilidade}

Uma nova geração de jovens planejadores de transporte verdes surgiu, jovens irritados em bicicletas, que estão inflamados com o fundamentalismo ambiental. Eles justificam suas ações em nome da sustentabilidade e, aparentemente, acima de qualquer censura por causa de seu zelo pelo meio ambiente e o respeito com o Planeta. Parece haver pouca compreensão da complexa e essencial natureza dos deslocamentos das pessoas, especialmente das mulheres e o fato de que o transporte público não fornece os trajetos, destinos e horários que homens e mulheres necessitam.

Como resultado, muitas mulheres se deslocam em torno das cidades - com dificuldade - usando suas habilidades de sobrevivência e conhecimento preciso 
dos horários dos ônibus locais, com tempo limitado para realizar suas tarefas. O transporte público é inadequado, caro, pouco confiável e pouco frequente. Como Roberts e Eldridge (2009) comentam (aludindo a MASSEY, 1998, p. 163) "grande parte da vida de muitas pessoas, mesmo no coração do Primeiro Mundo, ainda consiste na espera, em um ponto de ônibus com as suas compras, por um ônibus que nunca chega". Por isso, é impraticável sugerir que todos devem voltar para os transportes públicos, uma vez que os serviços já se deterioraram (HAMILTON, 2000; WDS, 2000) e raramente atendem às necessidades das pessoas. Alguns grupos nunca tiveram carros como prioridade, mas mesmo assim, descobrem suas necessidades deslocadas em favor de fornecer instalações de 'park and ride' para usuários predominantemente masculinos.

\section{Provisão de banheiros públicos em relação ao transporte}

\section{A Grande Estratégia de Banheiro da Cidade}

Embora seja impossível, e além do escopo deste trabalho mudar os sistemas de transporte, nós podemos pelo menos fazer recomendações. Por exemplo, a EUROFEM, uma influente rede de mulheres urbanistas da União Europeia, recomendou que devemos avançar no desenvolvimento de alternativas de superar as cidades zoneadas, de baixa densidade. Elas recomendam o planejamento para a 'cidade da vida cotidiana', que elas definem como a cidade de curtas distâncias, uso misto da terra urbana e múltiplos centros, tendo como o objetivo ideal localizações de instalações que levem plenamente em conta as considerações de gênero (EUROFEM, 1998; FCM, 2006). Tal estrutura da cidade iria beneficiar todos os grupos sociais, reduzir a necessidade de deslocamento, criar cidades mais sustentáveis que seriam mais acessíveis, criando, ao mesmo tempo, maior qualidade do ambiente urbano para todos. Proporcionaria mais empregos e facilidades em nível local e ajudaria a revitalizar áreas em declínio global (SKJERVEN, 1993).

Entretanto, não se pode 'por tudo abaixo e começar de novo'. Por enquanto, é preciso se dedicar às lacunas no sistema de transporte existente, procurando adicionar o 'elo perdido' isto é, a provisão de banheiros. Para isso, precisamos desenvolver um planejamento de uso de banheiros, uma estratégia espacial para a cidade como um todo (macro), para área local (meso) e para áreas locais, em nível de blocos (micro). Isso foi recomendado no passado
(GREED, 2003; GERSHENSON e PENNER, 2009) campanhas foram realizadas para tornar isso possível. A provisão de banheiros é um tópico do planejamento das cidades como qualquer outro sério e funcional uso da terra, que precisa ser planejado e organizado de forma racional, com base no levantamento da cada situação, análise e desenvolvimento de políticas de planejamento adequadas.

\section{Nível Macro - Cidade}

Para decidir onde localizar banheiros públicos de uma forma não sexista em toda a cidade é necessário levar em conta a natureza diferente dos padrões de deslocamento feminino. As mulheres são mais propensas a empreender deslocamentos em cadeia, desenvolvendo multitarefas, ao invés de mono deslocamentos. Assim como, a se deslocarem acompanhadas de filhos e outros membros da família, bem como a carregar compras e sacolas. Como dito anteriormente, um típico deslocamento diário, em cadeia de uma mulher, pode considerar o trajeto da casa para a babá, escola, trabalho e de volta do trabalho, à escola, talvez ainda para o dentista, para as lojas, para comprar alimentos essenciais e depois para casa. As mulheres que trabalham em bairros ou locais adjacentes, ou fora nos parques industriais, são mais propensas a fazer deslocamentos mais tangenciais do que focados para o centro da cidade, criando uma rede alternativa complexa de padrões de deslocamento. Tudo isso precisa ser levado em conta no planejamento da provisão de banheiros na cidade como um todo e deve ser parte de um processo mais amplo de integração das considerações de gênero na política de planejamento urbano. Segundo Greed (2005a, b) é necessário um completo repensar sobre zoneamento, políticas locacionais e de transportes que considerem os diferentes padrões de deslocamentos das mulheres.

Os deslocamentos, muitas vezes longos e com atrasos, levam a necessidade de instalações sanitárias em redes de transporte, notadamente quando são inadequadas (LOTH, 2010). De fato, como monitorado pela Organização Mundial de Banheiros, muitas extensões de prestígio dos sistemas de metrô da capital, como a Linha Jubilee em Londres, e novas rotas em Paris, Washington e Los Angeles, não possuem nenhuma provisão de banheiros públicos para os passageiros.

Quantos banheiros são necessários e onde? É importante realizar um levantamento de todos os banheiros ao quais o público tenha acesso tanto na rua quanto fora da rua e os resultados devem ser desagregados de acordo com gênero (GREED, 2003; 
BTA, 2008). Muitas autoridades locais não têm uma estratégia ou plano de provisão de banheiros e possuem pequena consciência das necessidades de banheiros em vários locais, resultando em uma política de localização fragmentada. Tais autoridades herdaram uma miscelânea de banheiros que foram construídos em épocas diferentes, por razões perdidas nas brumas do tempo. É vital desenvolver uma hierarquia de provisão de banheiros na cidade toda, com o maior nível de provisão nas áreas centrais, mas também em bairros e áreas onde as necessidades mais concentradas existam. Por exemplo, a estação ferroviária ou rodoviária do centro da cidade é, muitas vezes, a porta de entrada para o restante da cidade e, por isso, é muito importante que banheiros adequados sejam fornecidos como parte da estratégia integral de transporte para a cidade.

As mulheres são mais propensas a estarem fora de casa durante o dia, fazendo compras e realizando outras tarefas essenciais, mas sem o benefício de um escritório ou hotel conveniente onde possam voltar rapidinho, caso precisem do banheiro enquanto estiverem longe de casa. Assim, as mulheres vão exigir um maior nível de provisão do que os homens em alguns locais. Por exemplo, em locais em que as mulheres sejam a maioria, como usuárias do transporte público, pedestres e compradoras. Se alguém andar por um shopping e fizer uma contagem mental, é provável que as mulheres superem os homens em uma proporção de 20 homens para 80 mulheres. No entanto, a provisão de banheiros para as mulheres nos centros urbanos na 'melhor das hipóteses' (em casos raros) é provável que seja em níveis 'iguais'. Entretanto, geralmente, na proporção de provisão de banheiros é de 70 a 30, em favor dos homens. Não é de se admirar que haja longas filas para ao banheiro feminino, o que pesa no tempo diário gasto pelas mulheres.

Uma estratégia provisão de banheiros precisa levar em conta o tempo, bem como espaço urbano. Vivemos na era da cidade de 24 horas, a economia noturna e maior flexibilidade de padrões de trabalho diários. O sexismo é abundante na Inglaterra em relação ao aspecto da provisão de banheiros e as provisões de sanitários públicos municipais foram fechados a uma proporção de $40 \%$ nos últimos dez anos, trazendo problemas para mulheres que fazem compras, passageiros e todos que estão nas ruas durante o dia.

Em contraste, muitas autoridades locais têm introduzido mictórios de rua para os beberrões do sexo masculino que têm aumento do nível de sujeira da rua devido o consumo crescente de bebidas alcoólicas nos finais de tarde e à noite. Mas nenhuma solução alternativa é disponibilizada para as mulheres durante o dia. Ao desafiar vários funcionários públicos sobre a natureza sexista da provisão de banheiros, foi afirmado que essa política não é discriminatória, pois esses mictórios não são banheiros públicos em si, mas mecanismos que evitam a poluição da rua. O dever de igualdade de gênero (RTPI, 2003; GREED; REEVES, 2005, DCLG, 2007) não é uma referência para a política de acesso aos mictórios que, se estivessem disponíveis vinte e quatro horas por dia, seria uma solução melhor.

\section{Meso Nível - Distrital}

O próximo nível a considerar na hierarquia de provisão de banheiros na cidade é o nível de bairro local e o nível distrital, que pode ser caracterizado por sua própria rua ou local de compras, escolas, igrejas e instalações esportivas. A área pode variar consideravelmente de acordo com o tamanho da cidade como um todo, bem como com sua densidade e idade. É preciso considerar se existe realmente um centro local, visto que muitas cidades são cada vez mais descentralizadas e 'americanizadas' (KUNSTLER, 1994), embora Nova York pareça ser muito mais uma cidade 'europeia'.

Ao decidir que banheiros são necessários e onde, novamente é importante realizar um levantamento das necessidades dos usuários, seus padrões de deslocamento e atividades e, ainda desagregar as informações com base na idade. Diferentes tipos de pessoas têm acesso a banheiros em diferentes tipos de locais fora das ruas. Por exemplo, os homens podem encontrar banheiros disponíveis em bares, instalações desportivas e locais industriais. As crianças vão querer sanitários localizados em parques e áreas de lazer, em shoppings, mas também como um direito humano básico nas escolas. As mulheres idosas têm-nos dito a partir da pesquisa, que elas querem banheiros próximos aos correios e bibliotecas, e que cada cemitério deveria ter banheiros acessíveis para as viúvas que visitam os túmulos de seus maridos. Os homens mais velhos podem se sentir intimidados por mictórios públicos e querem a provisão de cubículos, que são acessíveis e privativos.

Há muito tempo as mulheres urbanistas recomendaram a introdução de edifícios comunitários 'multiusos' em áreas residenciais suburbanas (KUNSTLER, 1994; HAYDEN, 2002). As mães que trabalham teriam nessa área uma série de cuidados para com as crianças, idosos, suprimentos a serem comprados após a escola, juntamente com a disponibilidade de banheiros públicos. $\mathrm{O}$ fato de que $\mathrm{o}$ banheiro é construído isoladamente, de forma escondida entre edifícios. Isso pode ser um reflexo da 
nossa atitude sexista e elitista em relação a banheiros públicos, que precisam se tornar realidade. Os banheiros devem ser vistos como elementos de direito e da vida pública e não causadores de desordem. É preciso colocá-los em locais visíveis, no centro de praças e ao lado de importantes edifícios e não ter constrangimentos em relação a eles. Os banheiros podem ser visíveis e ter uma arquitetura fabulosa, sendo parte do projeto urbano (ROBERTS; GREED, 2001) e de cidades sustentáveis, habitáveis, acessíveis, com ruas de uso misto e vibrantes, à la Jane Jacobs (JONES, et al, 2007 ).

Todos também disseram que queriam banheiros localizados ao lado das principais estradas e nos estacionamentos do seu destino. Uma questão fundamental que surgiu em nossa pesquisa é a necessidade de, pelo menos, mínimas provisões básicas em regiões menos povoadas, periféricas e rurais (GREED; DANIELS, 2002). Até mesmo locais isolados podem, de repente, explodir em vida e, em seguida, o fator de intensidade de banheiros entra em jogo. Por exemplo, uma pequena povoação apática pode parecer uma candidata improvável para a construção de um alto nível de provisão de banheiros. Mas, uma vez por semana uma feira ou mercado pode aparecer no povoado e centenas de pessoas chegam com seus filhos e todos precisam de banheiros. Da mesma forma lugares bonitos e distantes, parques nacionais, locais à beira-mar, que são geralmente tranquilos, de repente podem ser inundados quando dez ônibus chegam 'de uma só vez' repletos de, predominantemente, mulheres, idosos, todos querendo usar o banheiro. Tal como acontece com esgotos e defesas contra inundações é importante construir banheiros para permitir o máximo de volume possível de pessoas. O 'fator intervalo' também precisa ser levado em conta. Em locais onde haverá um monte de gente querendo usar o banheiro de uma só vez, durante um curto espaço de tempo, como nos recreios escolares, intervalos de teatro, meio tempo de jogos, etc., então é muito importante fazer um alto nível de provisão, especialmente para as mulheres, que acabam na fila por muito tempo e perdem toda a segunda metade de atividades que estão sendo desenvolvidas.

As instalações desportivas são as piores para as mulheres. Enquanto os homens estão horrorizados com a ideia de que as mulheres deveriam ter mais banheiros e, é provável que seja dito que nenhum dinheiro está disponível, em contraste, oficialmente autorizada às provisões de banheiros em estádios de futebol está na base de 90:10 ou 80:20, na melhor das hipóteses, a favor dos homens (INGLIS, 1993). Em muitos dos estádios de esportes masculinos podem acontecer um festival pop ou uma reunião evangélica e como resultado a composição de gênero da multidão é susceptível de ser metade mulher, e assim não há banheiros suficientes para o sexo feminino. As soluções incluem uma abordagem mais flexível de conversão de banheiros masculinos em instalações para mulheres, e até mesmo, como na Escandinávia, se livrar totalmente de mictórios para que as instalações possam ser utilizadas por ambos os sexos.

Após anos de campanha, os requisitos de paridade sanitária na América do Norte já foram atingidos em alguns estados, mas isso levou a um grande ressentimento entre os homens quando eles descobrem que tem que ficar na fila também, e eles não aguentam como as mulheres (ANTHONY, 2001). No Reino Unido, há pouca orientação do governo sobre os níveis de provisão de banheiros públicos, e tem sido deixada ao critério das autoridades governamentais locais. Mas novas normas foram publicadas no ano passado pelo "comitê de instalações sanitárias do Instituto de Padrões Britânicos" (British Standards Institute) (BSI, 2010), como o número de banheiros que devem ser fornecidos para homens e mulheres. Este novo padrão foi produzido, depois de um processo muito longo e difícil, por um pequeno comitê de especialistas, com poucos membros do sexo feminino.

A provisão de banheiros em áreas locais deve ser cuidadosamente situada de modo a torná-lo utilizável por todos. Os sanitários não devem estar localizados fora da vista, pelos becos ou escondidos por arbustos. As instalações para 'Senhoras' e 'Senhores' não deveriam necessariamente ser localizadas ao lado do outro, especialmente se as instalações dos homens atrair comportamentos antissociais. Os banheiros devem ser concebidos de uma forma que sejam acessíveis, sem degraus, sem entradas estreitas e uma boa iluminação por dentro e por fora. Não há necessidade de isolar os banheiros de outros edifícios, integrando-as com o centro turístico local, quiosque de informações ou café pode reduzir o vandalismo e economizar custos.

Banheiros públicos podem ser 'reforçados' se eles forem alocados em forma de instalações compartilhadas, com agências de correios, delegacias e bibliotecas e de fato tal arranjo pode criar 'calma no olho da tempestade'. Colocá-los junto a cabines telefônicas e pontos de ônibus, já vulneráveis, onde dissolutos, jovens bêbados do sexo masculino, saem para passear e podem ter problemas com a justiça. Beber na rua (e urinar) é particularmente um problema em países do norte Europeu, como a Grã-Bretanha, onde temos a cultura baseada em beber 'cerveja', contra a mais refinada 'cultura do vinho' do Sul da Europa ou a idade mais elevada permitida para beber nos EUA. 


\section{Micro Nível - Detalhado}

As mulheres são as principais usuárias de sanitários públicos e metade dos usuários de banheiros domésticos, mas elas raramente são consultadas sobre o projeto de banheiros, o qual é baseado no modelo masculino de necessidade, e das dimensões ergonômicas do sexo masculino. Como vimos os banheiros das mulheres são uma reflexão tardia, um ostentação cara a ser considerada depois que as 'reais' necessidades dos homens são satisfeitas. (Por outro lado, se os urinóis são tão importantes para os homens, por que cada banheiro doméstico não tem um? Pois a maioria dos homens têm claramente dificuldade em acertar o vaso sanitário em suas próprias casas). É recomendável que o dobro do número de banheiros seja fornecido para as mulheres, mas calculado a partir de que valor base? Há muitos debates a respeito de quantos banheiros são necessários por população. Os membros da Associação Britânica de Sanitários têm recomendado que "uma autoridade local deve fornecer nada menos do que 1 cubículo para cada 500 mulheres e crianças do sexo feminino e um cubículo e um mictório para cada 1100 homens, e não menos do que um cubículo unissex para uso de pessoas com deficiência para cada 10.000 habitantes e não menos de uma instalação de trocador de fraldas unissex para cada 10.000 pessoas habitando na área" (CUNNINGHAN; NORTON, 1993). A 'população' relevante em questão também deve incluir usuários de transporte público habituais, turistas e visitantes, bem como residentes.

Esse padrão deve ser usado no cálculo de instalações em relação ao centro das cidades, ruas comerciais, necessidades de passageiros transporte ferroviário, terminais rodoviários, estacionamentos, etc. Esta é uma possibilidade, há outras fórmulas e padrões a serem encontrados em todo o Extremo Oriente, onde tem havido uma revolução de banheiros, como manifestado nas conferências anuais da Organização Mundial de Banheiros. Ao determinar os níveis de provisão de banheiros para mulheres e homens, os estudos precisam ser elaborados com base na bacia de capacitação, população residente, população flutuante/visitante, idade dos usuários e todos os tipos de variáveis. Novamente, a melhor solução é fazer um trabalho de pesquisa, descobrir o que os usuários precisam, perguntar o que as pessoas reais querem (MIYANISHI, 1996).

Tendo em conta as exigências de maiores níveis de provisão para as mulheres, a área a ser alocada para mulheres e homens seria totalmente diferente, com o bloco dos banheiros femininos parecendo substancialmente maior do que os dos Cavalheiros. Mas isso já seria o caso se apenas a relação de 1:1 de paridade fossem atingidas, porque as mulheres precisam ser providas de cubículos individuais, que ocupam mais espaço do que os mictórios masculinos, que podem acomodar um número muito maior de usuários em um espaço pequeno. Mas a diferença de área seria ainda mais acentuada se 2:1 de provisão, a favor das mulheres fossem dadas, como recomendado sob os novos padrões e como já é o caso nas zonas turísticas muito utilizados no Japão, onde as filas nos banheiros femininos não existem mais. A introdução do Dever de Igualdade de Gênero na Grã-Bretanha (REEVES; GREED, 2005) e a recente introdução da 'paridade de sanitários' em Nova York já deveriam ter tido resultados, mas há muitas lacunas e armadilhas (ANTHONY, 2001). Na Grã-Bretanha as novas regras não são retrospectivas e poucas instalações estão sendo construídas. Mas o 'espaço importa': o tamanho do bloco do sanitário e o número de cubículos reflete a estima e a posição das mulheres na sociedade. Dentro do banheiro, o design e as dimensões do cubículo sanitário é uma questão crucial, tendo em conta que as mulheres sempre usam o cubículo, enquanto os homens podem usá-lo apenas ocasionalmente.

Também quem viaja pode ter bagagem, malas, mochilas, carrinhos e outros itens volumosos que precisam ser levados com eles para o banheiro, a fim de evitar que sejam roubados. Portanto, nos banheiros deve haver um espaço adequado para as pessoas levarem seus pertences com elas. Vejamos os vários elementos. A porta é um importante componente e se a abertura é para dentro, pode reduzir área para o usuário virar e sentar no assento. Há vários exemplos de banheiros em que o ponta da porta encosta na parte frontal do sanitário, dificultando seu uso. Deve haver sempre uma área razoável entre a porta e o assento, pelo menos, 450 milímetros, de preferência mais. As portas dos banheiros dizem muito sobre a cultura de uma nação. Na América do Norte, especialmente nos EUA, geralmente há um enorme espaço debaixo da porta, provavelmente porque você não quer qualquer comportamento inadequado acontecendo entre os homens no banheiro masculino. Isso tem sido aplicado de maneira impensada nos banheiros das mulheres também? Em alguns países, as portas tem aberturas para ventilação e ninguém é tão rude a ponto de olhar para dentro. Há muitos banheiros no mundo sem absolutamente nenhuma porta, especialmente em países onde a vida é mais comunitária e a privacidade ainda não foi inventada.

Deveria haver espaço suficiente ao redor do vaso sanitário para se sentar no assento, sem se esfregar contra as paredes. Na Grã-Bretanha, muitas vezes, 
percebemos que existe um enorme rolo de papel higiênico na parede acima do vaso. Então, no outro lado, é provável que haja uma enorme lixeira de plástico que é para a eliminação de absorventes sanitários e tampões. Isto frequentemente encosta ou fica suspenso acima do assento tornando quase impossível sentar. A solução é um cubículo maior, com dutos de eliminação integrados na parede de trás, ou simplesmente um cordão sanitário, de $450 \mathrm{~mm}$ ao redor do vaso, onde nada pode ser colocado.

A disposição atual dos elementos é sexista, pois se supõe que a menstruação seja uma questão tão pequena que pode ser dispensada por uma lixeira temporária de plástico ao invés de um componente integral do encanamento sanitário e eliminação de resíduos. A chegada dessas lixeiras há alguns anos atrás foi o resultado de uma legislação ambiental inapropriada que classificava os resíduos sanitários, como resíduos clínicos, necessitando de coleta em uma lixeira especial. Ninguém se preocupou em resolver as implicações de espaço desta disposição dentro de um compartimento de banheiro já lotado.

Muitas mulheres não se sentam no vaso porque elas têm medo de sentar no resíduo de urina da ocupante anterior. Alguns banheiros públicos oferecem coberturas automáticas de papel nos assentos, o que é reconfortante, ao passo que, muitas mulheres vão usar papel higiênico para cobrir o assento antes de sentar, bloqueando assim os ralos. Os homens sempre deixam o assento para cima, embora eu tenha visto em meu catálogo de encomendas, 'Coisas Úteis', que agora você pode comprar um assento que desce sozinho depois de alguém urinar!

Mas por que estamos todos sentados? Esta é uma particularidade ocidental e o debate entre sentar ou agachar-se transcorre no âmbito da Organização Mundial de Banheiros. $\mathrm{O}$ agachamento é ergonomicamente mais eficaz (como o parto natural). Mas o agachamento é visto hoje como algo atrasado, rural e muçulmano (e, portanto, não cristão), quando na verdade, provavelmente a maioria da população mundial, particularmente nos países em desenvolvimento se agacha ao invés de sentar. $\mathrm{Na}$ verdade, apenas as nações desenvolvidas usam papel higiênico, limpar-se com água usando a mão esquerda é comum entre os muçulmanos e em várias outras culturas orientais. Um banheiro não sexista deve incluir a escolha de pelo menos um banheiro com bacia turca e fornecimento de água no cubículo. Onde o papel higiênico é oferecido, ele deve ser limpo e fácil de pegar, não comprimido em alguma engenhoca de plástico impenetrável que não vai desenrolar. Muitas mulheres usam papel higiênico para se secar após urinar e assim ele vai tocar uma de suas áreas mais íntimas. Não é de admirar que muitas mulheres carregam seu próprio papel e lenços de papel. Após ter usado o banheiro é importante fornecer instalações decentes de lavar e secar, com água quente e sabonete. $\mathrm{O}$ fornecimento de sistemas infravermelhos para abertura e fechamento do cubículo, sistemas de descarga e fluxo de água não é apenas não sexista, mas, mostra o respeito a todos os usuários. $\mathrm{O}$ comentário final sexista é dizer que há filas dos banheiros femininos, porque as mulheres gastam muito tempo fazendo sua maquiagem, na verdade esta não é nem mesmo uma declaração lógica. Em muitos banheiros públicos as mulheres teriam medo de demorar mais do que o necessário, por causa do medo de crimes e germes. Mas, é sempre mais fácil 'culpar as mulheres' e supor que elas são culpadas pelas filas em vez de fornecer mais instalações.

O cubículo sanitário não existe no isolamento, há uma necessidade de uma área de transição entre o cubículo e a rua. Isso é importante para a paz de espírito quando formar a fila e também é um local de esperar por amigos, de deixar um carrinho de bebê, ou agir como uma barreira para alcançar um maior nível de privacidade. As mulheres são muito cautelosas com as portas dos banheiros que se abrem diretamente para a rua, onde você não pode ver em que está pisando, ou quem está à espreita do lado de fora. Um simples olho mágico que dá para ver quem está na porta seria útil como encontrado em alguns banheiros no Extremo Oriente. Deveria ter muito espaço de circulação nos banheiros, espaço para cadeiras de rodas, bagagem, carrinhos de bebê, compras, e crianças, em nossa pesquisa algumas pessoas queriam trazer seus cães e bicicletas também.

Apesar de ser preferível ter blocos de banheiros separados para homens e mulheres (por razões culturais e práticas), para aqueles acompanhados por cuidadores do sexo oposto é necessário que haja instalações unissex também.

Ao invés de ter um banheiro especial para deficientes, há muito aspectos a favor de se ter cubículos sanitários maiores e integrados para portadores de deficiência dentro do bloco principal do banheiro. Na América do Norte, a Lei de Americanos com Deficiências e a Lei de Barreiras Arquitetônicas (Americans with Disabilities Act and Architectural Barriers Acts), juntamente com os padrões UFAS (Uniform Standards Acessibilidade Federal) garantem que um banheiro para pessoas com deficiência 'deve ser uma característica de todos os banheiros'. Muito progresso foi feito também em muitos países europeus, por exemplo, com as Leis contra a Discriminação por Deficiência (Disability Discrimination Acts) sendo passadas no Reino Unido 
(GOLDSMITH, 2000; IMRIE e HALL, 2001). Da mesma forma deveria haver instalações adequadas para crianças e fraldários para bebês.

Há debates ainda, quanto ao fato da necessidade de haver instalações para amamentação dentro dos banheiros. Em um mundo não sexista ideal, provavelmente esta seria uma atividade absolutamente natural que deveria acontecer ao ar livre. Contudo, na atual situação cultural esta provisão tem sido discutida, para proteger as lactantes de olhares indiscretos.

Embora todos estes aspectos discutidos sejam importantes no cotidiano, no momento, o banheiro público 'pântano padrão' continua a ser inadequado para muitos e, fundamentalmente sexista em sua concepção, sendo que uma abordagem mais acessível deve ser necessária (HANSON, et al, 2007). Todos os tipos de pessoas são 'deficientes' pela ênfase atual em satisfazer as necessidades do homem jovem, saudável, de quadris estreitos que carrega apenas um jornal enrolado nas mãos. A estratégia é atender a uma diversidade de necessidades dentro das 'mesmas' instalações, adotando uma abordagem universalista para design de sanitários (GOLDSMITH, 2000), que inclui as necessidades de todos, resultariam em verdadeiros banheiros de palácios, que estariam abertos 24 horas com uma gama completa de instalações localizadas em locais centrais muito usados.

Este nível de provisão não seria possível em todos os lugares, mas a estratégia é de proporcionar uma hierarquia de provisão de banheiros com base nas demandas locais, com pelo menos um nível mínimo de provisão em cada ponto crítico/local de conflito de banheiro.

O programa atual de espaço interno parece ser baseado em um desejo de controle, redução de custos, economias, padronização das unidades para menos e nunca para mais. Por exemplo, é prática comum substituir uma linha tradicional de banheiros por uma APC (Automatic Public Convenience). APCs são as melhores instalações unissex, mas não deveriam ser fornecidas como a única opção disponível, pois elas são impróprias para uso intenso. Mesmo as versões maiores tem pouco espaço para carrinhos e ocupações compartilhados (mãe e filho). A maioria das APCs não são gratuitas e cada vez mais tem que se pagar para usar o banheiro. Mas pode-se argumentar que as mulheres já pagam por esses serviços públicos através dos seus impostos locais e é hora de terem algo em retorno. Mas, as mulheres ainda são vistas como uma despesa extra e longe de fazer banheiros gratuitos para todos, agora, vemos as catracas de volta, e todos tendo que pagar.

\section{Conclusão: Um Bem Essencial ou uma Perda de Recursos}

Devemos encarar o fato de que banheiros públicos custam dinheiro e parafraseando Milton Friedman, em última análise, "não há tal coisa, como um xixi gratuito" e banheiros custam dinheiro para manter. Embora, sem dúvida, já pagamos por banheiros e outros serviços públicos, através dos nossos impostos nacionais e locais, recursos financeiros para banheiros não estão no topo da agenda. Projetar e construir um banheiro não sexista é apenas metade da batalha. Um banheiro permanecerá utilizável se for bem cuidado, limpo e gerenciado. Temos argumentado a partir da pesquisa que os funcionários de banheiros são essenciais para reduzir o vandalismo e fornecer uma presença essencial, mantendo os olhos no estabelecimento.

Se você tiver banheiros muito frequentados, então, o projeto pode ser mais aberto e acessível, ao passo que se você tiver banheiros desocupados, então, é necessário projetar o banheiro como uma fortaleza para evitar danos. A natureza do projeto depende fundamentalmente se o bloco do banheiro é frequentado ou não. Eu uso a palavra 'ocupado' propositadamente como acho que é uma tendência perturbadora de que onde há funcionários de banheiros eles são geralmente do sexo masculino, nos banheiros femininos, também, o que pode ser bastante desanimador .

Os fornecedores municipais de banheiros públicos constantemente se queixam de que não há dinheiro para investir em sanitários. Contudo, gastam o dinheiro dos contribuintes em exemplos muito criticados de arte pública, salários enormes para altos funcionários, instalações desportivas principalmente para os homens $\mathrm{e}$ várias outras iniciativas extravagantes. Eu diria que não há realmente uma falta de dinheiro, mas sim, é tudo uma questão de prioridades e, portanto, é uma questão de perspectiva cultural e experiência de vida dos próprios legisladores. Não há tal coisa de dinheiro do governo, é todo o nosso dinheiro arrecadado dos impostos locais e nacionais. Muitos argumentariam que já pagaram por nossos banheiros públicos através dos nossos impostos e por quê devemos pagar a segunda vez no ponto de entrega? Banheiros públicos são um dos poucos benefícios concretos que as mulheres, idosos e pessoas com deficiência realmente dão valor e eles ficam muito angustiados ao descobrir que, apesar de aumentos enormes nos impostos locais, essas instalações tão necessárias estão sendo fechadas. Por quê isso não os deixa mais irritados? Com certeza a paciência, a confiança e a obediência aos poderes 
são os maiores pecados a partir da perspectiva feminista e nunca vão resultar em 'igualdade urinária'. Apesar dos olhares que recebo nas filas de banheiros femininos, eu gosto de entrar um pouco em 'evangelismo de banheiro', falando sobre os direitos femininos a um público cativo. Parafraseando Marx, muitas mulheres estão sofrendo de falsa consciência [de classe] sanitária.

Por quê não é um grande problema político? E, reciprocamente, por quê o governo não leva a sério os banheiros? O que aconteceu com o orgulho cívico manifestado em gerações anteriores? Por quê não somos nós 'esplêndidos em nossas vias públicas'? Grande parte da resposta se resume ao sexismo e ao fato de que muitos políticos, decisores e gestores têm muito pouca ideia das vidas das pessoas comuns, nós somos invisíveis para eles.

É muito importante trazer o programa de sustentabilidade para o nível de vida cotidiana das pessoas comuns e certificar-se de que os banheiros sejam fornecidos para permitir que todos, especialmente as mulheres, mas também os idosos, deficientes e pessoas com crianças pequenas e bebês, possam acessar e utilizar facilmente os sistemas de transportes urbanos e, portanto, serem capazes de desempenhar as suas funções e jornadas diárias.

A provisão de banheiros públicos é, muitas vezes, visto como uma perda de recursos, um poço sem fundo em investimentos financeiros. Com vista a alcançar uma melhor provisão de banheiros é importante discutir o negócio, quer dizer que 'banheiros significam negócios' (BTA, 2008). Se existir uma provisão adequada de banheiros então as pessoas vão ficar mais tempo na cidade, elas vão gastar mais dinheiro em compras, entretenimento e turismo. Os cidadãos serão mais saudáveis e custarão ao empregador e aos provedores de saúde menos dinheiro. O caso da sustentabilidade funciona bem também. Nós argumentamos a partir de nossa pesquisa que, se o governo quer que as pessoas saiam de seus carros e voltem para os transportes públicos, caminhadas e ciclismo, então, os banheiros públicos são o elo perdido. Isto porque se as pessoas não têm o seu carro elas simplesmente não podem ir até ao posto de serviço mais próximo para usar os banheiros, ou dirigir ao restaurante fast food mais próximo. Banheiros são essencialmente uma instalação local que tem que estar a uma curta distância. Estes argumentos são particularmente importantes nas cidades onde há planos para introduzir custos de congestionamento ou outras restrições sobre o transporte em automóvel particular.

Não se pode esperar que as pessoas usem o transporte público, a menos que seja acessível e equipado com as comodidades necessárias, incluindo banheiros e, claro, preços razoáveis. Na verdade, 'tudo se resume a banheiros em última análise' e 'toda a vida humana está lá '.

* Tradução de Silvana Hilgemberg

${ }^{2}$ A Organização Mundial de Sanitários estima que cerca de 2 bilhões de pessoas no mundo têm provisões inadequadas de banheiros, além da falta de água corrente, eletricidade e infraestrutura moderna (MARA, 2006; GEORGE, 2008; BLACK e FAWCETT, 2008).

${ }^{3}$ Quando a família dispõe de um automóvel, em geral, ele fica sob a guarda e uso masculino.

${ }^{4}$ A Pesquisa do Uso do Tempo no Reino Unido (UKTUS - The UK Time Use Survey) realizada pelo Instituto Nacional de Estatística tem monitorado a quantidade exata de tempo utilizado por mulheres e homens nos cuidados com as crianças durante vários anos (EOC, 2005; KALENKOSKI, et al, 2005).

5 Expressão que significa um estacionamento dentro dos terminais de transporte público que facilitam a integração entre o transporte privado (carro) e o público (trens, metrôs ou ônibus).

${ }^{6}$ Outro exemplo de sexismo impensado.

\section{Referências}

AGE, Concern. Nowhere to go: Public provision in the UK, London. Age Concern, 2007

ANTHONY, Kathryn. Designing for diversity: Gender, race and ethnicity in the architectural profession. Chicago: University of Illinois Press, 2001

BAGILHOLE, Barbara . Understanding equal opportunities and diversity: The social differentiations and intersections of inequality. Bristol: Policy Press, 2009

BLACK, Maggie; FAWCETT, Ben. The last taboo: Opening the door on the global sanitation crisis. London: Taylor and Francis and Earthscan, 2008

BOOTH, C; DARKE, J; YEANDLE, Sue. Changing Places: Women's lives in the city. London: Paul Chapman, 1996. 
BRUNTLAND Report . Our common future, world commission on environment and development. Oxford: Oxford University Press, 1987.

BS1. BS 6465 Part 4: Code of practice for the provision of public toilets. London: British Standards Institute, 2010.

BTA. Better Public Toilets: A providers' guide to the provision and management of 'away from home' toilets. Winchester: British Toilet Association, 2008.

BUCKINGHAM-HATFIELD, Susan. Gender and Environment . London: Routledge, 2000.

CAVANAGH, Sheila. Queering Bathrooms: Gender, sexuality, and the hygienic imagination. Toronto: University of Toronto Press, 2010.

CIC. Gathering and reviewing data on diversity within the construction professions. London: Construction Industry Council, London and the University of the West of England Bristol, 2009.

COLEMAN, Charlotte. Women, transport and cities: an overview an agenda for research, In Women and the City: Visibility and Voice in Urban Space (DARKE, J; LEDWITH, S; WOODS, R) Palgrave, London, pp. 83-97,2000.

CUNNIngham, Susan; NORTON, Christine. Public inconveniences: Suggestions for improvements. London: All Mod Cons \& the Continence Foundation, 1993.

DARKE, Jane; LEDWITH,Sue; WOODS,Roberta. Women and the city: Visibility and voice in urban space. Oxford: Palgrave, 2000.

DCLG. PPS1: Delivering Sustainable Development, Planning Policy Statement. London: Department of Communities and Local Government, 2005.

DCLG. Gender equality scheme. London: Department of Communities and Local Government, 2007.

DFT. Public transport gender audit. London: Mobility Unit, Department of Transport, 2000.

DOBBS, Lynn. Wedded to the car: women, employment and the importance of private transport. Transport Policy. v. 12, Issue 3, pp. 266-278, 2005.
EOC. Time use and childcare. London: Equal Opportunities Commission, available at Disponível em $:<$ http://www.dad.info/b/assets /time_use.pdf $>$ ) Acesso 16 abril 2011

ESRC. Britain in 2011: The state of the nation. Swindon: Economic and Social Research Council, Swindon, (research undertaken annually), 2011.

EUROFEM. Gender and human settlements conference on local and regional sustainable human development from a gender perspective: Conference Proceedings of the Eurofem Network (European Women in Planning). Eurofem, Hämeenlina, Finland, 1998.

FCM. A city tailored to women: The role of municipal governments in achieving gender equality. Montreal: Federation of Canadian Municipalities available at Disponível em : www.ville.montreal.qc.ca/femmesetville Acesso: 2006.

FINCHER,Ruth; IVESON, Kurt. Planning and diversity in the city. London: Palgrave Macmillan, 2008 .

GILROY, Rose. Places that support human flourishing: lessons from later life, Planning Theory and Practice, v.9, No.2, pp 145-163, 2008.

GEORGE, Rose. The big necessity: Adventures in the world of Human waste. London: Portobello, 2008.

GERSHENSON, Olga; PENNER, Barbara. Ladies and gents: Public toilets and gender. Philadelphia: Temple University Press, 2009.

GLA. An urgent need: The state of London's toilets. London: London Assembly and Greater London Authority, Health and Public Services Committee, 2006.

GOLDSMITH, Selwyn. Universal sesign: A manual of practical guidance for architects. Oxford: Architectural Press, 2000.

GREED, Clara. Women and planning: Creating gendered realities. London: Routledge, 1994.

GREED, Clara. Planning for women and other disenabled groups, Environment and Planning A, v. 28, p. 573-588, 1996. 
A relação generificada entre o zoneamento urbano do transporte público e as implicações para a provisão de banheiros públicos

GREED, Clara. Introducing planning. London: Athlone, 2000.

GREED, Clara. Inclusive urban design: Public toilets. Oxford: Architectural Press, 2003

GREED, Clara. Overcoming the factors inhibiting the mainstreaming of gender into spatial planning policy in the United Kingdom. Urban Studies,v 42, n 4, pp. $1-31,2005$

GREED, Clara. An Investigation of the effectiveness of gender mainstreaming as a means of integrating the needs of women and men into spatial planning in the United Kingdom. Progress in Planning, Manchester, vl. 64, Part 4, pp 239-321, 2005.

GREED, Clara. A Place for Everyone: Report on mainstreaming gender into spatial planning Manchester. Oxfam UK Poverty and Regeneration Regender.Programme, 2007

GREED, Clara. Are we there yet?: Women and transport revisited, Gendered Mobilities, Uteng,P.T.; Cresswell, T. (eds)). Aldershot: Ashgate, chapter 16, pp. 243-256, 2008.

GREED,Clara; DANIELS,Isobel. User and provider perspectives on public toilet provision. Nuffield Trust funded research, Occasional Paper, University of the West of England, Bristol, 2002.

GREED,Clara; REEVES, Dory. Mainstreaming equality into strategic spatial policy making: are town planners losing sight of gender? Construction Management and Economics. Special Issue on Diversity and Equality in Education, v.23, No.10, pp. 1059-1070, 2005.

HAMILTON, Kerry. Public transport audit london. London: DETR Mobility Unit undertaken by University of East London, 2000.

HAMILTON, Kerry., JENKINS, Linda; HODGSON, Frances; TURNER, Jeff. Promoting gender equality in transport. Manchester: Equal Opportunities Commission, Manchester, Working Paper, n 34, 2005.

HAMMERSLEY, Martyn; ATKINSON, Paul. Ethnography: Principles in practice. London: Tavistock, 2002.

HANSON, Susan; PRATT, Geraldine. The Friction of distance and gendered geographies of employment.
Gender, Work and Space. London: Routledge chapter 4 ,pp. 93-119, 1995.

HANSON, Julienne; BICHARD, Jo-Anne; GREED, Clara. The accessible toilet resource manual. London: University College London, 2007.

HARVEY, David. Social justice and the city. London: Arnold, 1975

HAYDEN, Dolores. Redesigning the american dream. New York: Norton, 2002.

HENSHER. David; REYES, April. Trip-chaining as a barrier to the propensity to use public transport, Transportation,v, 27, n.4, pp 341-361, 2010.

HINE, J; GREICO, M. Scatters and clusters in time and space: implications for delivering integrated and inclusive transport. Transport Policy, v. 10, pp 299360, 2003.

IMRIE,Robert; HALL, Petter. Inclusive Design: Designing and developing accessible environments. London: Spon, 2001.

INGLIS, Simon. Toilet facilities at stadia: Planning, design and types of installation. London: Sports Council in association with the Football Trust, 1993.

JARVIS, Hellen; KANTOR, Paula; CLOKE, Jonathan. Cities and gender, London: Routledge, 2009.

JONES, Peter; ROBERTS, Marion; MORRIS, Linda. Rediscovering mixed-use streets: the contribution of local high streets to sustainable communities. Bristol: Policy Press, 2007

KALENKOSHI, Charlene; RIBAR, David; STRATTON, Leslie. Parental Child Care in Single Parent, Cohabitating, and Married-Couple Families: Time-Diary Evidence from the United Kingdom, The American Economic Review, v 95, No.2, pp 194$194,2005$.

KUNSTLER, James. The Geography of Nowhere: the rise and decline of American's man-made landscape. New York: Touchstone,1994.

KWAN, Mei-Po. Gender, the Home-Work Link, and Space-Time Patterns of Non-Employment Activities. Economic Geography. v. 75, Issue4, pp. 370-394. October, 1999 
LENCLOS, Marie. Inclusive design: Access to London transport. London: Royal College of Art, 2002 .

LITTLE, Jo; PEAKE, Linda; RICHARDSON, Pat. Women in cities: Gender and the urban environment. London: Macmillan, 1988.

LOTH, Marion. The provision of train toilets on inter-city European Union trains. Delft: Technological University of Delft, the Netherlands, 2010 .

MARA, D.Modern engineering interventions to reduce the transmission of diseases caused by inadequate domestic water supplies and sanitation in developing countries. Building Services and Engineering Research and Technology, v 27, no 2, pp 75-84, 2006.

MATRIX. Making Space: Women and the man-made built environment. London: Pluto, 1984.

MASSEY, Doreen. Spatial divisions of labour: social structures and the geography of production. London: Macmillan, 1984.

MASSEY, Doreen. Space, Place and Gender. Cambridge: Polity Press, 1998.

MCGUCKIN, Nancy; MURAKAMI, Elaine. Examining trip-chaining behaviour: comparison of travel by men and women. Transportation Research Board of the National Academies. v, 1693, pp 79-85, 2007.

MIYANISHI, Yutaka. Comfortable public toilets: Design and maintenance manual. Toyama: City Planning Department, Japan, 1996.

MOLOTCH, Harvey; NOREN, Laura . Toilet: Public restrooms and the politics of sharing. New York: New York University Press, 2010.

ONS. Social trends. London: Office of National Statistics, 2010.

PANELLI, Ruth. Social geographies: From difference to action. London: Sage, 2004.

PICKUP, Laurie; WHIPP, Richard. (eds) . Gender, transport and employment: the Impact of Travel Constraints. Aldershot: Avebury, 1989.
REEVES, Dory. Planning for diversity: Policy and planning for a world of difference. London:Routledge, 2005.

ROBERTS, Marion. Living in a man-made world. London: Routledge, 1991.

ROBERTS, Marion; ELDRIDGE, Adam. Planning the night-time economy. London: Routledge, 2009.

ROSENBLOOM, R. Trip chaining behaviour: and comparative and cross-cultural analysis of the travel patterns of working mothers. GRIECO, M., PICKUP, L., and WHIPP, R. (eds.) Gender, Transport and Employment. Avebury: Oxford Studies in Transport, chapter 4, pp.75-87, 1989.

RTPI . Gender mainstreaming toolkit (D. Reeves \& C. Greed (eds.), London: Royal Town Planning Institute, London, Disponível em : < www.rtpi.org.uk $>, 2003$.

SCHMOKER, Jan-Dirk; FENGMING, Su; Noland, Robert. An analysis of trip-chaining among older London residents. Transportation, v 37, No.1, pp 105-13, 2010.

SKINNER, Christine. Coordination points: a hidden factor in reconciling work and family life. Journal of Social Policy, v. 34, pp 99-119, 2005.

SKJERVEN, Randi . Manual of alternative municipal planning. Oslo: Ministry of Environment, 1993.

STIMPSON, Catharine; DIXLER, Elsa; NELSON, Martha; YATRAKIS, Kathryn. (eds.) Women and the american city. Chicago: University of Chicago Press, 1981.

TUC. Women and Work: Gender inequality in the north east labour market. TUC: London, 2002.

UN. The Rio declaration: United conference on the environment at Rio de Janeiro: Conference proceedings. New York: United Nations, 1992.

UTENG, Tanu Priya.; CRESSWELL, Tim. Gendered Mobilities. Aldershot: Ashgate, ch.16, pp. 243-256, 2008.

WARBURTON, A. Sex and the city: A study into the gender equality duty and women and planning in urban areas of England. Leeds Metropolitan 
A relação generificada entre o zoneamento urbano do transporte público e as implicações para a provisão de banheiros públicos

University, unpublished MA Town and Regional Planning Dissertation, 2009.

WDS. Women and local transport plans. London: Women's design service and see. Disponível em < www.gendersite.org >, 2000.

WDS. Cycling for women. London: Women's Design Service, 2005.

WHATMORE, S; LITTLE, Jo. Gender and geography. London: Association for Curriculum Development, 1988. 